\title{
Homeoprophylaxis: The Great Misunderstanding
}

\author{
George Vithoulkas ${ }^{1}$ \\ ${ }^{1}$ Greece \\ Homœopathic Links 2016;29(2):111-112.
}

\begin{abstract}
Address for correspondence George Vithoulkas, International Academy of Classical Homeopathy, Alonissos, Northern Sporades, Greece (e-mail: george@vithoulkas.com).
\end{abstract}

\author{
Abstract \\ Keywords \\ - homeoprophylaxis \\ - vaccination
}

This article is a transcript of a lecture on homeoprophylaxis given by Professor Vithoulkas at the International Academy of Classical Homeopathy, Alonissos, which he kindly edited and agreed to be reproduced for this issue of Homeopathic Links.

\section{Issues Concerning Homeoprophylaxis}

Prof. George Vithoulkas ${ }^{1}$ : I want to talk to you about what is called lately homeoprophylaxis and clarify certain issues concerning this matter. There is a general idea of the remedy Arnica being used before and after an operation. Many homeopaths advise, take Arnica before operation so you don't have much bleeding and then take Arnica afterwards to stop bleeding.

This is entirely wrong. Why? Because we use Arnica as a blood thinner. So if you have a clot of blood, it dissolves this clot. When you have a blow and there is an extravasation of blood and there are bruises with areas that are becoming blue, it means that the blood has created a lot of clot, and then you give Arnica, and like a miracle, these clots are dissolved. Why? Because Arnica is acting like Coumarin but better and faster than Coumarin, as there are no side effects.

But if Arnica is thinning the blood, it means that Arnica is contraindicated before an operation because, if anything, they will have more bleeding.

You see the illogical thinking of some people and also their misinformation?

Not only that. But you may get some people who say "We had tried and researched and we have found out that Arnica helps'. How they found out that Arnica helps if they cannot measure the bleeding before and without Arnica and the bleeding after Arnica?

But it is a fact that when you have a heart attack because of a blood clot, then the first remedy they may think to give is Arnica. Do you understand the misunderstandings that have taken place in the teaching of different schools?

Now the Times of London wrote an article in which they said, 'Homeopathy is a voodoo medicine'. Why? The journalist wrote, 'Listen to this: homeopaths claim that they can give a remedy as a prophylactic to the different epidemic diseases'. From where did he have such information? Because some homeopaths have written books, articles, etc. saying we have the possibility to give a remedy as a prophylaxis. That was taken to mean 'I give you a remedy and if an epidemic comes, like chicken pox or rubella or whooping cough, you are protected'. Do you believe you are protected? Of course not, and then the Times is right when saying this is 'voodoo medicine'. What is your reason for believing that giving a remedy-let us say Thuja or whatever, Morbillinum etc.-that it will protect you when the epidemic will come after a year or two?

Then the argument from some homeopaths is, 'but Hahnemann said that when there was an epidemic of scarlet fever during that time he gave Belladonna as a prophylactic so the people would be protected from scarlet fever'. See now, the misunderstanding of what Hahnemann said and how this has been misinterpreted and presented as a possibility for prophylaxis.

Hahnemann saw that a lot of people who were getting scarlet fever needed Belladonna as a remedy. So he thought, why not give Belladonna to everybody so that we may have less casualties. He thought he was doing a prophylaxis. What he was doing was giving a remedy in the beginning of the scarlet fever so this fever would not develop fully. It was like giving the right remedy in the very beginning of the disease and this was a curative action, not a prophylactic one in the meaning we have today for vaccinations and prophylaxis. During the epidemic, the genius of the epidemic-that means the remedy that was indicated in most of the cases-will act as a curative remedy. This is totally different from saying that we will give you a remedy and you will be protected from different epidemics like smallpox, chickenpox, mumps, scarlet fever etc.

The homeopathic remedy will act only if the symptoms are similar to the remedy. If the symptoms of the organism are
DOI http://dx.doi.org/ 10.1055/s-0036-1582469. ISSN 1019-2050. (c) 2017 Thieme Medical and Scientific Publishers Private Ltd.
License terms

()(1) $\Theta \circledast$ 
not similar, it is like giving a wrong medicine to a patient. It will have no effect. On the first situation, when the symptoms are similar, the remedy will cure because it fits on an organism that is already starting to become sick with symptoms of Belladonna. In the case where you give the remedy to a healthy individual outside of an epidemic and expect it to act when the epidemic will manifest after months or years, this is totally wrong and there will be no effect.

So how can one maintain that, by giving you a remedy today, the next year when the epidemic will come, you will be protected?

If you want to try to protect while the epidemic is there, then find, after your 10 first cases, which is the genius epidemicus and if there is such a remedy running through the cases, try to give this in the beginning of the epidemic and record the effects in a detailed manner and with objectivity.

In my book, The Science of Homeopathy, ${ }^{2}$ there is a chapter on vaccination. I have written this book in 1976 and still these ideas are valid to a great extent. During that time, I made a full analysis of who is going to be protected and how he is going to be protected. I let you read it, but now I can say only this: If a person is really protected by conventional vaccinations, that means the vaccination caused his immune system to be compromised and therefore this specific epidemic cannot affect him according to my theory 'Levels of Health'.

What I want you to understand is that homeopathy cannot make you so sick with a remedy that you will never get the epidemic. This is a mechanism, a simple mechanism. Can we, with homeopathy, claim to do this? No. The only thing we can claim is that during the epidemic we can give a common remedy for the epidemic, hoping that it will act.

Where are the double-blind tests so that we could support such claims?

My idea is that certain people are prone to have a big reaction with the conventional vaccination and that some will have side effects. Therefore, my idea is, before you vaccinate, you should find out the sensitivities of the immune system and detect the children who, if vaccinated, could develop dangerous side effects.

To do this, they can start today evaluating the immune system of the children before and after the vaccinations to find the differences and the parameters that made a child enter a pathologic state.

The argument is 'but they live longer now'. Yes, they live longer. But what is the quality of life that they will have?

We don't want to vaccinate until we will find out if the child can be safely vaccinated. Once the child is sick, you treat the child. The argument is 'but the poliomyelitis was killing a lot of people and paralysed them'. Yes, but they did not have homeopathy. They did not have any means to fight.

But this is not homeoprophylaxis. It is homeocuring. It is curing with homeopathy. We have to find out whether a child would be vaccinated and not have a dramatic effect on his health. There are certain signs that we can observe in a child, and if a child has these signs, he/she should be excluded. There are some signs that we can find out if we really do research in this.

Today genetics have progressed quite a lot. For example, if in the DNA you find a predisposition for a neuromuscular disorder, you must say this child should not take polio vaccination. Today we have the technology to take such measures.

Behind all this is the fear of death. Behind all this is our fear of dying. Why? Because we have not been educated at all on what the meaning of life is and what the meaning of death is. We don't know. We are afraid of the unknown.

I conclude that we homeopaths have no alternative to vaccinations and I think I have explained this issue properly.

Now, I want to read you something very short from the British Medical Journal, June 14, 2007. Concerning the vaccine Gardasil which is given to young girls to protect them from developing cancer.

The HPV vaccine which has been given to girls age 11 to 12 to prevent cervical cancer in later life may be a killer. So far, three young girls have died after been vaccinated and there have been 1,637 adverse reactions reported in less than a year.

1,637 reported, never mind the unreported. And it continues...

In Australia 25 girls at the same school who had been given their first HPV vaccine last month experience headache, nausea, and 4 of them ended in the hospital. Otherwise there are no side effects. The vaccine continues...

It is the British Medical Journal, a prestigious medical journal, reporting this.

So we have a problem with vaccinations really and we have to solve it quickly before we find out that we have damaged deeply the human race.

\section{Editor's Note}

Prof. Vithoulkas and the editor (Isaac Golden) debated this topic in 2007 over four editions of www.hpathy.com. This debate is still available to read in the Hpathy archive. ${ }^{3}$

The very relevant issue of whether HP actually works by suppressing the immune system (like vaccines), or works only because it treats what is present during an epidemic, or actually works because it effectively treats specific inherited weaknesses which would otherwise prevent the vital force from protecting individuals if they are exposed to the targeted diseases, is discussed in the final chapter of the editor's book The Complete Practitioners Manual of Homeoprophylaxis. ${ }^{4}$

\section{References}

1 Vithoulkas G. Homeopathic Prophylaxis, Vaccinations, AIDS, Provings. https://www.youtube.com/watch?v=S3aGFBxV6Uc. Accessed February 29, 2016

2 Vithoulkas G. The Science of Homeopathy. New York, NY: Grove Press; 1981

3 http://hpathy.com/homeopathy-papers/reply-to-isaac-golden. Accessed February 29, 2016

4 Golden I. The Complete Practitioners Manual of Homeoprophylaxis. Haarlem, The Netherlands: Emryss Publishing; 2012 